ISSN 1112-9867

Available online at

http://www.jfas.info

\title{
THERMODYNAMIC PARAMETERS OF SOLUTIONS OF SILDENAFIL CITRATE IN SOME ORGANIC SOLVENTS AT DIFFERENT TEMPERATURES
}

\author{
S. Baluja* and K. Bhesaniya \\ Physical Chemistry Laboratory, Department of Chemistry, \\ Saurashtra University, Rajkot-360005 (Gujarat), India.
}

Received: 24 February 2014 / Accepted: 23 May 2014 / Published online: 30 June 2014

\begin{abstract}
The solubility of Sildenafil citrate in some organic solvents; hexane, toluene,1-butanol and 1,2 dichloroethane has been determined using gravimetric method over different temperature range $(298.15 \mathrm{~K}$ to $328.15 \mathrm{~K})$ at one atmospheric pressure. The modified Apelblat and Buchowski-Ksiazczak $\lambda h$ equations were used to correlate the experimental solubility data. Further, various thermodynamic parameters have been evaluated from these solubility data.
\end{abstract}

Key Words: Solubility, Organic solvents, Sildenafil citrate, Thermodynamic parameters

\section{INTRODUCTION:}

Sildenafil citrate 1-[4-ethoxy-3-(6,7-dihydro-1-methyl- 7-oxo-3-propyl-1H-pyrazolo[4,3-d] pyrimidin-5-yl) phenylsulfonyl]-4-methylpiperazine is a drug which has been used to treat erectile dysfunction and pulmonary arterial hypertension [1]. It relaxes the arterial wall, leading to decreased pulmonary arterial resistance and pressure. It was developed and is being marketed by the pharmaceutical company Pfizer. It is well known by the name Viagra. It is metabolised by liver enzymes and excreted by both the liver and kidneys. Further, it is a selective inhibitor of cyclic guanosine monophosphate-specific phosphodiesterase [2]. Professional athletes also use this drug to enhance their performance [3].

Author Correspondence, e-mail: shipra_baluja@rediffmail.com

ICID: 1111608 
Due to its important applications, it was thought of interest to study its solubility in different solvents which may help its use in other fields. Thus, in the present study, the solubility of Sildenafil citrate was determined in hexane, toluene, 1-butanol and 1,2 dichloroethane at different temperatures ( $298.15 \mathrm{~K}$ to $328.15 \mathrm{~K})$ by a gravimetric method. Further, various thermodynamic parameters were evaluated from the solubility data.

\section{EXPERIMENTAL SECTION}

- Materials:

Sildenafil citrate [Fig. 1], with mass purity of 0.99 was purchased from Ami Life Sciences Pvt. Ltd. Vadodara (India). The solvents; hexane, toluene,1-butanol and 1,2 dichloroethane were analytical grade reagents, which were purified by fractional distillation. The purity was determined by using Shimadzu gas chromatography/mass spectrometry (Model No QP-2010) and was found to be greater than $99.5 \%$.<smiles>CCCc1nn(C)c2c(=O)[nH]c(-c3cc(S(=O)(=O)N4CCN(C)CC4)ccc3OCC)nc12</smiles>

Fig.1. Chemical structure of Sildenafil citrate

\section{- Solubility measurement}

The gravimetric method was used to study the solubility. For each measurement, an excess mass of Sidnafil citrate was added to a known mass of solvent. Then equilibrium cell was heated to a constant temperature with continuous stirring. After, at least $3.5 \mathrm{~h}$, the stirring was stopped and the solution was kept at a constant temperature for $2 \mathrm{~h}$. The equilibrium time of 2 $\mathrm{h}$ is optimized by checking the concentration of the solution at different intervals of time. After $2 \mathrm{~h}$, the change in concentration was less than $1 \%$, so saturated solution was assumed to be in equilibrium. Upper portion of this clear solution was filtered by a membrane $(0.45 \mathrm{~m})$ and kept in a weighed vial. The vial with solution was quickly weighed to determine the mass of the sample and placed in vacuum oven at $313.15 \mathrm{~K}$ to fully evaporate solvents. When the mass of the residue reached at constant value, the final mass was recorded. All of the masses were taken using an electronic balance (Mettler Toledo AB204-S, Switzerland) with an uncertainty of $\pm 0.0001 \mathrm{~g}$. At each temperature, the measurement was conducted three times, 
and an average value was used to determine the mole fraction solubility of solute $(x)$ in solvents by using equation (1) and given in Table 2 .

$$
x=\frac{m_{2} / M_{2}}{r_{2} / M_{2}+m_{1} / M_{1}}
$$

where $M_{1}$ and $M_{2}$ is the molar mass of solvent and drug respectively. $m_{1}$ and $m_{2}$ are weights of solvent and drug in the solution respectively.

\section{RESULTS AND DISCUSSION}

The experimental solubility data of drug in hexane, toluene, 1-butanol and 1,2 dichloroethane are summarized in Table 1 at different temperatures. It is observed that solubility increases with temperature in all the solvents. The variation of solubility as a function of temperature is also shown in Fig. 2. It is observed that over all, solubility is maximum in toluene and minimum in dichloroethane. The solubility of drug in these solvents is compared with dielectric constant and dipole moments of the solvents (Table 2). Both hexane and toluene have lower dielectric constants and dipole moments as compared to those for 1-butanol and dichloroethane. This is reverse of solubility results. This suggests the solubility of studied drug is reverse of dielectric constants and dipole moments. However, among hexane and toluene, solubility is higher in toluene (having higher dielectric constant and dipole moment) whereas among 1-butanol and DCE, solubility is higher in -butanol (having higher dielectric constant and dipole moment). This indicates that other factors also contribute to dissolution of a substance in a solvent. 
Table 1. Experimental mole fraction solubilities $(x)$, calculated mole fraction solubilities $\left(x^{a / b}\right)$ and relative deviation $(R D)$ of Sildenafil citrate in studied solvents.

\begin{tabular}{|c|c|c|c|c|c|}
\hline$T / K$ & $x \times 10^{4}$ & $x^{a}{ }_{c} \times 10^{4}$ & 100RD & $x^{b}{ }_{c} \times 10^{4}$ & 100RD \\
\hline & \multicolumn{5}{|c|}{ Hexane } \\
\hline 298.15 & 4.00 & 4.15 & -3.70 & 3.46 & 13.54 \\
\hline 303.15 & 4.80 & 4.35 & 9.34 & 4.42 & 7.99 \\
\hline 308.15 & 4.70 & 4.93 & -4.97 & 5.60 & -19.04 \\
\hline 313.15 & 6.10 & 6.01 & 1.41 & 7.04 & -15.33 \\
\hline 318.15 & 7.50 & 7.85 & -4.62 & 8.78 & -17.10 \\
\hline 323.15 & 11.50 & 10.91 & 5.12 & 10.89 & 5.32 \\
\hline \multirow[t]{2}{*}{328.15} & 16.00 & 16.10 & -0.65 & 13.41 & 16.18 \\
\hline & \multicolumn{5}{|c|}{ Toluene } \\
\hline 298.15 & 3.00 & 2.60 & 13.32 & 2.97 & 1.04 \\
\hline 303.15 & 5.00 & 5.73 & -14.59 & 5.69 & -13.81 \\
\hline 308.15 & 9.00 & 11.63 & -29.25 & 10.68 & -18.66 \\
\hline 313.15 & 26.00 & 21.87 & 15.88 & 19.64 & 24.45 \\
\hline 318.15 & 44.00 & 38.25 & 13.07 & 35.44 & 19.45 \\
\hline 323.15 & 64.00 & 62.48 & 2.38 & 62.80 & 1.88 \\
\hline \multirow[t]{2}{*}{328.15} & 87.00 & 95.69 & -9.99 & 109.34 & -25.68 \\
\hline & \multicolumn{5}{|c|}{ n-Butanol } \\
\hline 298.15 & 0.40 & 0.396 & 0.89 & 0.46 & -16.01 \\
\hline 303.15 & 0.60 & 0.635 & -5.87 & 0.63 & -5.37 \\
\hline 308.15 & 1.00 & 0.939 & 6.09 & 0.85 & 14.72 \\
\hline 313.15 & 1.30 & 1.287 & 0.99 & 1.14 & 12.36 \\
\hline 318.15 & 1.60 & 1.643 & -2.69 & 1.51 & 5.73 \\
\hline 323.15 & 1.90 & 1.962 & -3.26 & 1.98 & -4.20 \\
\hline \multirow[t]{2}{*}{328.15} & 2.25 & 2.200 & 2.23 & 2.58 & -14.53 \\
\hline & \multicolumn{5}{|c|}{$D C E$} \\
\hline 298.15 & 0.25 & 0.281 & -12.30 & 0.34 & -37.22 \\
\hline 303.15 & 0.60 & 0.495 & 17.44 & 0.49 & 18.08 \\
\hline 308.15 & 0.80 & 0.789 & 1.36 & 0.70 & 12.98 \\
\hline 313.15 & 1.05 & 1.142 & -8.77 & 0.97 & 7.14 \\
\hline 318.15 & 1.45 & 1.510 & -4.17 & 1.35 & 6.82 \\
\hline 323.15 & 1.80 & 1.835 & -1.95 & 1.85 & -2.98 \\
\hline 328.15 & 2.15 & 2.059 & 4.25 & 2.52 & -17.15 \\
\hline
\end{tabular}

Table 2. Dielectric constants and dipole moments of the solvents at $293.15 \mathrm{~K}$.

\begin{tabular}{|c|c|c|c|c|}
\hline & Hexane & Toluene & 1-butanol & DCE \\
\hline $\begin{array}{c}\text { Dielectric } \\
\text { constant }\end{array}$ & $1.89(20)$ & $2.38(25)$ & $17.50(25)$ & $10.35(25)$ \\
\hline $\begin{array}{c}\text { Dipole } \\
\text { moments }\end{array}$ & $0.08(25)$ & $0.375(25)$ & $1.66(20)$ & $1.20(30)$ \\
\hline
\end{tabular}




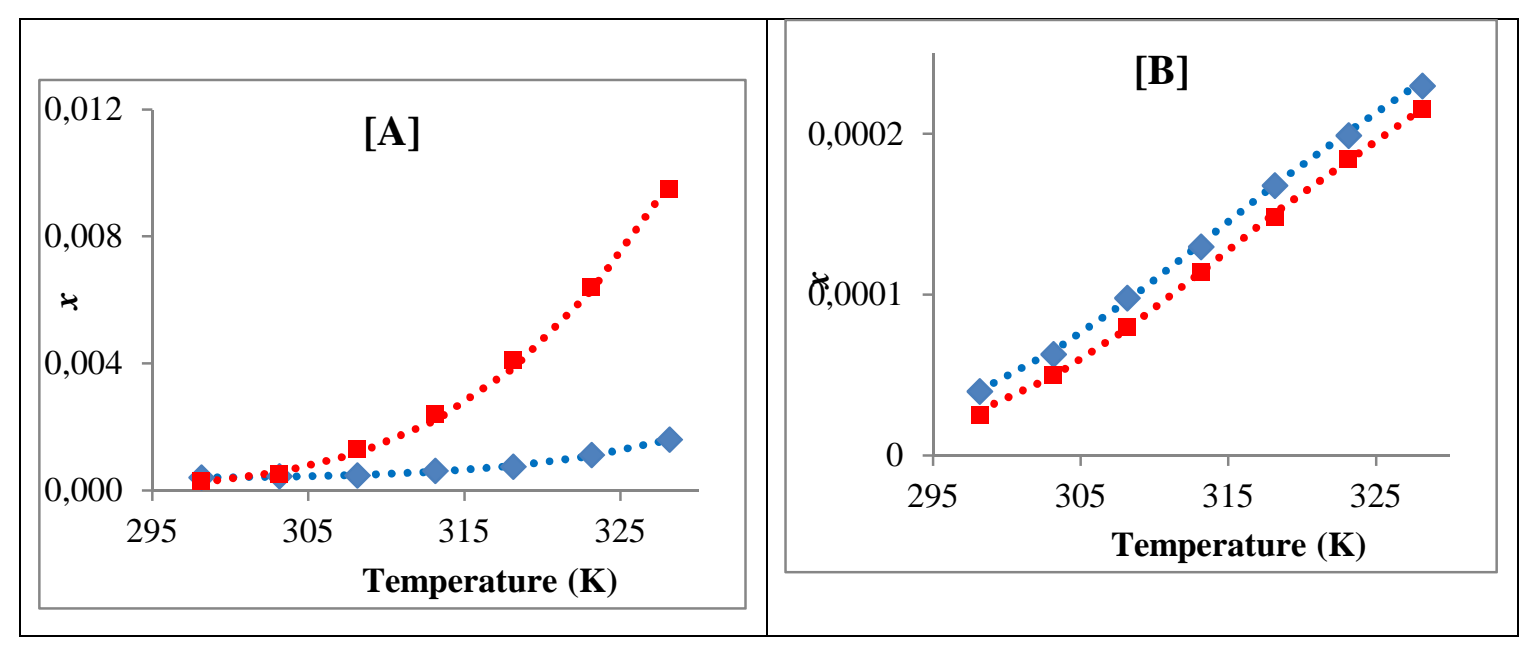

Fig.2. Variation of mole fraction solubilities $(x)$ with temperature $(T)$ for Sildenafil citrate in different studied solvents. [A] in Hexane and Toluene ; [B] in 1-butanol and dichloroethane . Corresponding dotted lines are for solubilities calculated by eq 2 .

The temperature dependence of solubility in a solvent is described by the modified Apelblat equation $[4,5]$.

$$
\ln x=A+B / T+C \ln (T)
$$

where $x$ is the mole fraction solubility of drug at temperature $T$. $A, B$ and $C$ are parameters determined by least square analysis from the correlation of the experimental data and values of these parameters are given in Table 3. Using these parameters, mole fraction solubilities $\left(x_{c i}^{a}\right)$ for drug were evaluated and are given in Table1.

The Buchowski-Ksiazczak $\lambda$ h equation $[6,7]$ describes the solid-liquid equilibrium behavior by only two adjustable parameters $\lambda$ and $h$.

$$
\ln \left(1+\frac{\lambda\left(1-x_{c i}^{b}\right)}{x_{c i}^{b}}\right)=\lambda h\left[\frac{1}{(T / K)}-\frac{1}{\left(T_{m} / K\right)}\right]
$$

where $T$ and $T_{m}$ represents the experimental and melting temperatures of drug in Kelvin. $\lambda$ and $h$ are the model adjustable parameters, which are given in Tables 4 . 
Table 3. Parameters A, B and C of eq (2), ARD of eq (5) and RMSD of eq (6) of Sildenafil citrate in studied solvents.

\begin{tabular}{|c|c|c|c|c|c|}
\hline Solvent & $\boldsymbol{A}$ & $\boldsymbol{B}$ & $\boldsymbol{C}$ & $\boldsymbol{R M S D}$ & $\mathbf{1 0 0} \boldsymbol{A A D}$ \\
\hline Hexane & -1987.23 & 88006.01 & 295.61 & $3.56576 \mathrm{E}-05$ & 0.369 \\
\hline Toluene & 1444.82 & -77278.22 & -209.54 & $4.75 \mathrm{E}-04$ & -1.31 \\
\hline I-butanol & 1653.66 & -81833.01 & -243.84 & $4.71532 \mathrm{E}-06$ & -0.23 \\
\hline DCE & 2123.65 & -104399.48 & -313.11 & $7.49607 \mathrm{E}-06$ & -0.59 \\
\hline
\end{tabular}

Table 4. Parameters $\lambda$ and $h$ of eq (3), ARD of eq (5) and RMSD of eq (6) of Sildenafil citrate in studied solvents

\begin{tabular}{|c|c|c|c|c|}
\hline Solvent & $\lambda$ & $\boldsymbol{h}$ & $\boldsymbol{R M S D}$ & $\boldsymbol{1 0 0} \boldsymbol{A A D}$ \\
\hline Hexane & 0.066 & 4421 & $1.34 \mathrm{E}-04$ & -3.5174 \\
\hline Toluene & 356.71 & 11763 & $9.39 \mathrm{E}-04$ & 2.0493 \\
\hline I-butanol & 0.0360 & 5592 & $1.57 \mathrm{E}-05$ & 1.0327 \\
\hline $\boldsymbol{D C E}$ & 0.0787 & 6503 & $1.63 \mathrm{E}-05$ & 0.6884 \\
\hline
\end{tabular}

Using these parameters, mole fraction solubility $\left(x_{c i}^{b}\right)$ for drug in different solvents at different temperatures was evaluated and was compared with experimental mole fraction solubility and are given in Table 1. The relative deviation (RD) between experimental and calculated solubility values is calculated by the following equation (4) and is listed in Table 1.

$$
R D=\left(x_{i}-x_{c i}^{a / b}\right) / x_{i}
$$

where $x_{i}$ is experimental solubility and $x_{c i}^{a / b}$ is calculated solubility. For Apelblat eq. (2), calculated solubility is $x_{c i}^{a}$ whereas for Buchowski-Ksiazczak eq. (3), it is $x_{c i}^{b}$.

The, average relative deviations (ARD) and root-mean-square deviations (RMSD) were also calculated for modified Apelblat and $\lambda \mathrm{h}$ relations using equations (5) and (6) and are listed in Tables 3 and 4.

$$
\begin{aligned}
& A R D=\frac{1}{N} \sum_{i}^{N}\left(x_{i}-x_{c i}^{a / b}\right) / x_{i} \\
& R M S D=\left[\sum_{i=1}^{N}\left(x_{c i}^{a l b}-x_{i}\right)^{2} / N-1\right]^{1 / 2}
\end{aligned}
$$

where $N$ is the number of experimental points. 


\section{- Thermodynamic functions of dissolution}

The dissolution of a substance in a solvent is associated with changes in thermodynamic functions such as standard Gibb's energy ( $\left.G_{s o l}\right)$, standard enthalpy $\left(\Delta H_{s o l}\right)$ and standard entropy $\left(\Delta S_{s o l}\right)$ of solution which are calculated from experimental solubility data. The changes that occur in the solute during dissolution process can be explained by these thermodynamic functions.

According to the Krug et al. [8] approach, the following modified van't Hoff expression [9] was used to determine the enthalpy of solution $\left(\Delta H_{s o l}\right)$.

$$
\left(\partial \ln x / \partial\left(1 / T-1 / T_{h m}\right)\right)_{P}=-\Delta H_{s o l} / R
$$

where $H_{s o l}$ is the standard enthalpy energy charge for the solution process and $T_{h m}$ is the harmonic mean of the experimental temperatures, which is evaluated by following equation.

$$
T_{h m}=\frac{n}{\sum_{1}^{n}\left(\frac{1}{T}\right)}
$$

where $\mathrm{n}$ is the number of experimental temperatures [10]. In the present case, $T_{h m}$ value is $312.83 \mathrm{~K}$. The value of $\Delta H_{\text {sol }}$ was obtained from the slope of the plot of $\ln x$ versus $(1 / T$ 1/312.83). The standard Gibbs energy change for the solution process ( $\mathrm{G}_{\text {sol }}$ ), considering the approach proposed by Krug et al., is calculated at $T_{h m}$ by following equation.

$$
G_{s o l}=-R \cdot T_{h m} \cdot \text { Intercept }
$$

in which, the intercept was obtained from the plot of $\ln x$ versus $\left(1 / T-1 / T_{h m}\right)$.

Finally, from these evaluated $\Delta H_{\text {sol }}$ and $\Delta G_{s o l}$ values, the entropies of solutions $\left(\Delta S_{\text {sol }}\right)$ were obtained from equation $[8,11]$

$$
\Delta S_{s o l}=\frac{\Delta H_{s o l}-\Delta G_{s o l}}{T_{h m}}
$$

\begin{tabular}{|c|c|c|c|c|}
\hline Parameters & Hexane & Toluene & 1-Butanol & $D C E$ \\
\hline G/kJ.mol ${ }^{-1}$ & 18.92 & 16.31 & 23.67 & 24.08 \\
\hline $\mathrm{H} / \mathrm{kJ} \cdot \mathrm{mol}^{-1}$ & 36.76 & 97.79 & 46.49 & 54.06 \\
\hline S/J.mol-1. $K^{-1}$ & 57.01 & 260.48 & 72.94 & 95.85 \\
\hline
\end{tabular}

Table 5. Thermodynamic parameters of dissolution of drug in studied solvents. 
Table 5 summarizes these evaluated thermodynamic parameters. It is found that enthalpy of dissolution $\left(\Delta H_{s o l}\right)$ is positive for all the solvents suggesting thereby endothermic dissolution of drug. This indicates that the interactions between drug and solvent molecules are more powerful than those between the solvent molecules. Thus, the newly formed bond energy between drug and solvent molecule is not powerful enough to compensate the energy needed for breaking the original association bond in various solvents [12, 13]. The Gibbs energy of dissolution $\left(\Delta G_{s o l}\right)$ is also positive for the studied solvents suggesting that the dissolution process is spontaneous [14]. Further, comparison of solubility and $\Delta G_{s o l}$ trend for different solvents shows that the order of $\Delta G_{s o l}$ is reverse of solubility data. The higher positive $\Delta G_{s o l}$ decreases the solubility in all studied solvents. The entropy of dissolution $\left(\Delta S_{\text {sol }}\right)$ is also positive, which indicates favorable entropy of solubilisation for drug in studied solvents [15]. This may be due to different molecular structures and space conformations between solute and solvent molecules. As Sildenafil citrate molecules contain groups of different nature like $-\mathrm{N}-, \mathrm{C}=-\mathrm{O},-\mathrm{NH}, \mathrm{SO}_{2}$, the dissolution of this drug in various solvents may cause various interactions such as dipole-dipole, hydrogen bonding, hydrophobic interactions, stereoscopic effects, etc. [16]. Due to these interactions, may be the drug disrupts the alignment of solvent molecules which increases entropy.

\section{CONCLUSION}

The solubility of Sildenafil citrate is higher in toluene and decreases with increase in dielectric constant and dipole moment. The solubility is found to increase with temperature and dissolution of this drug is spontaneous and endothermic phenomenon.

\section{Nomenclature}

$\mathrm{m}=$ weight

$\mathrm{M}=$ molar mass

$x=$ Mole fraction

$\mathrm{A}, \mathrm{B}$ and $\mathrm{C}=$ Parameter for Apelblet equation

$\mathrm{T} / \mathrm{K}=$ Absolute temperature in Kelvin

$\mathrm{R}=$ Gas Constant

$T_{h m}=$ Harmonic mean of the experimental temperatures

$G_{\text {sol }}=$ Standard Gibb's energy $\left(\mathrm{kJ} . \mathrm{mol}^{-1}\right)$

$\Delta H_{\text {sol }}=$ Standard enthalpy $\left(\mathrm{kJ}_{\mathrm{m}} \mathrm{mol}^{-1}\right)$ 
$\Delta S_{\text {sol }}=$ Standard entropy $\left(\mathrm{J} . \mathrm{mol}^{-1} \cdot K^{-1}\right)$

$H_{s o l}=$ Standard enthalpy energy charge for the solution process

$\lambda, h=$ Parameters for Buchowski-Ksiazczak equation

\section{Superscripts}

$\mathrm{RD}=$ Relative deviations

$\mathrm{ARD}=$ Average relative deviations

RMSD $=$ Root-mean-square deviations

\section{REFERENCES}

[1] Boolell, M., Gepi-Attee, S., Gingell, J.C., Allen, M.J., Sildenafil, a novel effective oral therapy for male erectile dysfunction, Br. J. Urol., 184, 1996, 63-72

[2] Boolell, M., Allen, M.J., Ballard, S.A., Sildenafil: an orally active type 5 cyclic GMPspecific phosphodiesterase inhibitor for the treatment of penile erection dysfunction. Int. J. Impot. Res., 8, 1996, 47-52

[3] Daily news New York 10 June 2008, Roger Clemens, host of athletes pop Viagra to help on field performance.

[4] Mora, C.P., Martinez, F., Solubility of naproxen in several organic solvents at different temperatures, Fluid Phase Equilibria., 255, 2007, 70-77

[5] Sunsandee, N., Hronec, M., Stolcova, M., Leepipatpiboon N., Pancharoen, U., Thermodynamics of the solubility of 4-acetylbenzoic acid in different solvents from 303.15 to 473.15 K, J. Mol. Liq., 180, 2013, 252-259.

[6] Buchowski, H., Ksiazczak, A., Pietrzyk S., Solvent activity along a saturation line and solubility of hydrogen-bonding solids, J. Phys. Chem., 84, 1980, 975-979.

[7] Ksiazczak, A., Moorthi, K., Nagata, I., Solid-solid transition and solubility of even nalkanes, Fluid Phase Equilib., 95, 1994, 15-29.

[8] Krug, R.R., Hunter, W.G, Grieger, R.A., Enthalpy-entropy compensation. 2. Separation of the chemical from the statistical effects, J. Phys.l Chem., 80, 1976, 2341-2351.

[9] Yu, Q., Ma, X., Gao, W., Determination of the solubility, dissolution enthalpy and entropy of suberic acid in different solvents, Fluid Phase Equilibria., 330, 2012, 44-47.

[10] Aragon, D.M., Ruidiaz, M.A., Vargas, E.F., Bregni, C., Chiappetta, D.A., Sosnik, A., Martinez, F., Solubilitty of the antimicrobial agent triclosan in organic solvents of different hydrogen bonding capabilities at several temperatures, J. Chem. Eng. Data. 53, 2008, 2576-2580. 
[11] Bustamante, S.P., Romero, A.P, Escalera, B., Reillo, A., Enthalpy-entropy compensation for the solubility of drugs in solvent mixtures: paracetamol, acetanilide and nalidixic acid in dioxane-water, J. Pharm. Sci., 87, 1998, 1590-1596.

[12] Kalsi, P.S., Organic reactions and their mechanisms, Second ed., New Age int. (P) ltd., New Delhi, 2004, 119.

[13] Panteli, E.K., Voutsas, E.C., Solubilities of cinnamic acid esters in ionic liquids, J. Chem. Eng. Data. 54, 2009, 812-818.

[14] El-Bindary A.A., El-Sonbati, A.Z., El-Mosalamy, E.H., Ahmed, R.M., Potentiometric and thermodynamic studies of azosulfonamide Drugs. X, Chem. Pap. 57, 2003, 255-258.

[15] Filippa, M.A., Gasull, E.I., Ibuprofen solubility in pure organic solvents and aqueous mixtures of cosolvents: Interactions and thermodynamic parameters relating to the solvation process, Fluid Phase Equilibria., 354, 2013, 185-190.

[16] Prausnitz, J.M., Lichtenthaler, R.N., Azevedo, E.G, Thermodynamics of Fluid Phase Equilibria ( $3^{\text {rd }}$ Edition), Prentice Hall PTR, Upper Saddle river, New Jersey, 1999.

\section{How to cite this article:}

Baluja S. Bhesaniya K. Thermodynamic parameters of solutions of sildenafil citrate in some organic solvents at different temperatures. J Fundam Appl Sci. 2014, 6(1), 106-115 